\title{
Evaluation of the Permanence of Flame Accelerating Material on Burned Material with GC- MS Analytical Techniques
}

\author{
Claudio De Maio \\ Ministry of Interior, Italian National Fire Corps, Rome 00184, Italy \\ Corresponding Author Email: claudio.demaio@vigilfuoco.it
}

https://doi.org/10.18280/ijsse.110424

Received: 14 March 2021

Accepted: 20 July 2021

\section{Keywords:}

CBRN, HazMat, GC-MS, flame accelerating, benzene, firefighters, SPME, $H S$

\begin{abstract}
The aim of the work is to evaluate the permanence, understood as a presence detected by the analyzes, after a burn, of the flame-accelerating material used to start a fire, even in largely burnt residues, in order to be able to recognize, even in the investigative context, whether the fire was caused by an accident or if it was facilitated by the emission (voluntary or non- voluntary) of a flame-accelerating substance.

The analytical technique used to give answers to this is the use of the gas chromatographmass spectrometer (GC-MS), which allows to detect the presence of flame accelerators even in small quantities in the samples.

A series of burnt material samples will be reproduced in a controlled environment, originally containing flame-accelerating materials and then compared to burnt samples without flame-accelerating agents.

The results will be obtained through GC-MS analysis with the headspace (HS) and fiber (SPME) method, in order to evaluate, in greater detail, which of the two methods is the best performing to achieve the objective.

As final result, the SPME fiber is very performing for the goal to be achieved, because it is able to detail the flame accelerating compounds found.
\end{abstract}

\section{INTRODUCTION}

If we consider the destructive nature of the fire event, we understand how the investigation of the causes that originated it is an extremely complex activity that often sees the investigators but also the firefighting professionals, operating in the context of scenarios characterized by levels damage to structures and materials such as not to allow a reconstruction, if not partial, of the state of the places before the fire $[1,2]$.

The greater the ability to collect information on the scenario under investigation, interpreting, for example, the signs left by the fire or carrying out an appropriate activity for the search and identification of any accelerators present [3], and the higher the probability that the analysis of the event leads to the identification of the cause, through an objective reconstruction of the event $[4,5]$.

- It is obvious that the presence of flame accelerators (in this work we will evaluate benzene) gives important information to the analysis work as it directs investigations towards an arson or in any case a voluntary act [6].

In this work the "flame accelerator persistence" assumption will be considered valid if, following GCMS analysis of the sample [7], a benzene peak will still be visible in its spectrogram $[8,9]$.

This, transposed in the case of real activities, would allow us to affirm with a large degree of certainty that the benzene found in the sample contributed to the fire and that it was therefore introduced (voluntarily or not voluntarily) into the material which was then burned [10-12].

\section{SUBSTANCES}

Aromatic compounds are all those organic compounds, which contain one or more aromatic rings in their structure. The presence of these rings gives them particular reactivities [13].

Among the aromatic compounds, the main one is benzene, which has the brute formula C6H6. Its structure is planar and has six carbon atoms arranged at the vertices of a regular hexagon [14].

Benzene is a natural constituent of petroleum, but it is also synthesized from other chemical compounds found in petroleum itself. It has remarkable solvent properties; at room temperature and atmospheric pressure it is in the form of a highly flammable colorless volatile liquid with a characteristic odor (Figure 1) [15].<smiles>c1ccccc1</smiles>

Figure 1. Benzene molecule 


\section{METHOD AND SEQUENCE OF OPERATIONS}

To achieve the objectives of the Study, the AGILENT GCMS was used [16].

An Agilent 7890A Series GC connected to a 5975C mass selective detector (combined) was used to carry out GC/MS analysis. Splitless injector and the interface were maintained at $300^{\circ} \mathrm{C}$ and $340^{\circ} \mathrm{C}$ respectively [17]. Helium gas was used as carrier gas (at constant inlet pressure). The oven temperature was programmed from $50^{\circ} \mathrm{C}$ to $350^{\circ} \mathrm{C}(2-10 \mathrm{~min})$ at $10^{\circ} \mathrm{C} / \mathrm{min}$. The GC contained an HP-5MS 5\% phenyl methyl siloxane phase fused silica column with a diameter of $15 \mathrm{~m} \mathrm{X} 0.25 \mathrm{~mm}$, $0.25 \mu \mathrm{m}$ and was directly inserted into the ion source. A full scan at $70 \mathrm{eV}$ from m/z 50 to 800 was carried out to obtain the electron impact (EI) spectra [18-20].

It is a Gas Chromatograph - Mass Spectrometer, used by the Regional Advanced CBRN team of the Milan Fire Headquarters, which provides the detailed molecular profile of organic compounds that are identified by comparison with standard compounds or mass spectra libraries (Figure 2).

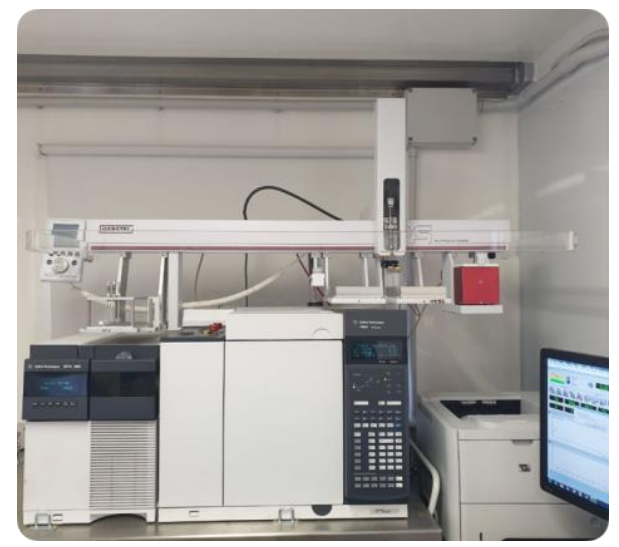

Figure 2. Gas chromatograph

Four samples were prepared with $1 \mathrm{ul}$ of benzene in $1 \mathrm{~cm} 2$ of cotton tissue, plus 1 positive control and 1 negative control (blank) [21].

The HS extraction procedures for the VOCs were carried out using $20 \mathrm{~mL}$ headspace vials (Agilent, Santa Clara, USA) and $250 \mathrm{~mL}$ polypropylene vials (Plaszom, Orlenas, Brazil) with caps for sampling [22-23].

The SPME extraction of volatile compounds was carried out by manual solid-phase microextraction using a $1-\mathrm{cm}$ long fiber (Supelco Co., Bellefonte, USA) coated with $30 \mu \mathrm{m}$ divinylbenzene/carboxen/polydimethylsiloxane

(DVB/CAR/PDMS) [24]. The fiber was exposed to the sample's headspace at $45^{\circ} \mathrm{C}$ for $60 \mathrm{~min}$. Prior to the first extraction, the fiber was conditioned at $270^{\circ} \mathrm{C}$ for $1 \mathrm{~h}$ in the injector port of the gas chromatograph. Between analyses, the fiber was reconditioned at $240^{\circ} \mathrm{C}$ for $15 \mathrm{~min}$ (desorption time of $4 \mathrm{~min}$ ) [25-27].

Sequence of operations:

1. Samples I and II were burned, taking care of completely burning the tissue (Figure 3).

2. Samples III and IV (and the two controls) were closed in order to enhance benzene vapors;

3. The burned and unburned samples were analyzed by both headspace (HS) and fiber (SPME) methods (Figure 4);

4. The spectrograms obtained were compared in order to assess both the presence of benzene and the quality of the result with respect to the two techniques used [28].

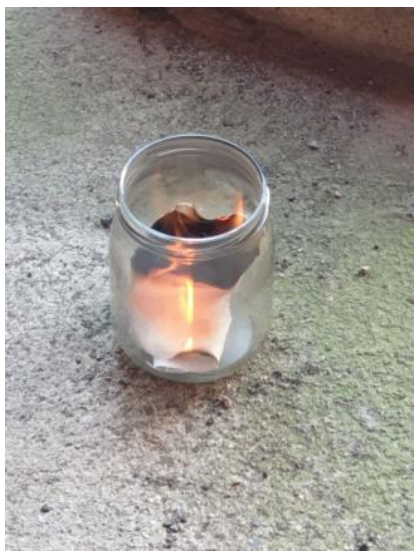

Figure 3. The sample is burned

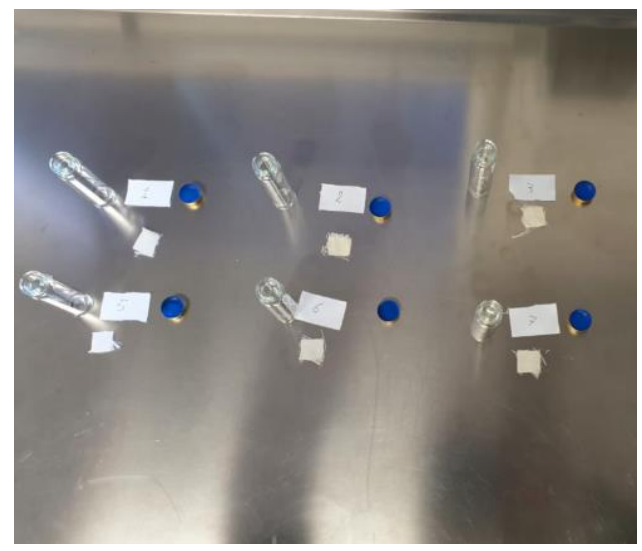

Figure 4. Preparation of the vials that will contain the sample for $\mathrm{GC} / \mathrm{MS}$ analysis

\section{RESULTS}

Following analysis, the GC-MS curves turned out to be as follows (Figures 5-8).

Benzene was found in all 4 samples.

The obvious differences are explained in the conclusions.

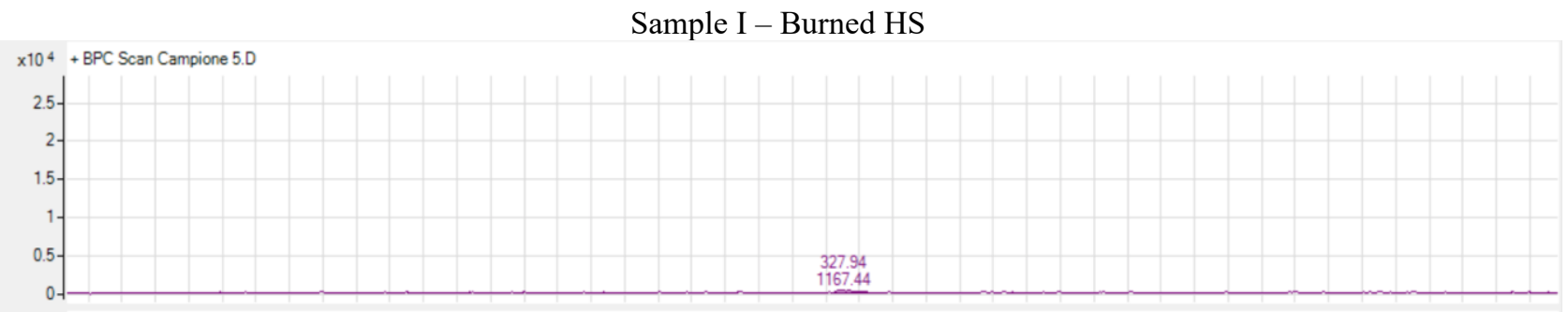

Figure 5. Sample I Spectrogram 


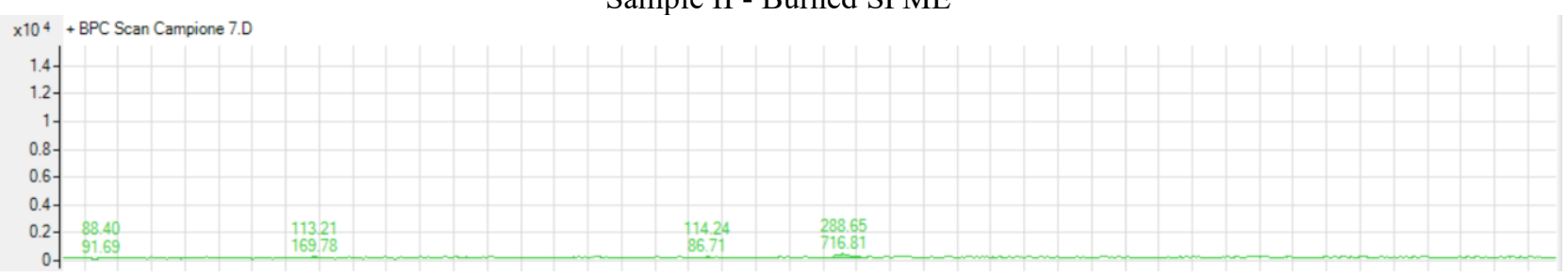

Figure 6. Sample II Spectrogram

Sample III - SPME unburned

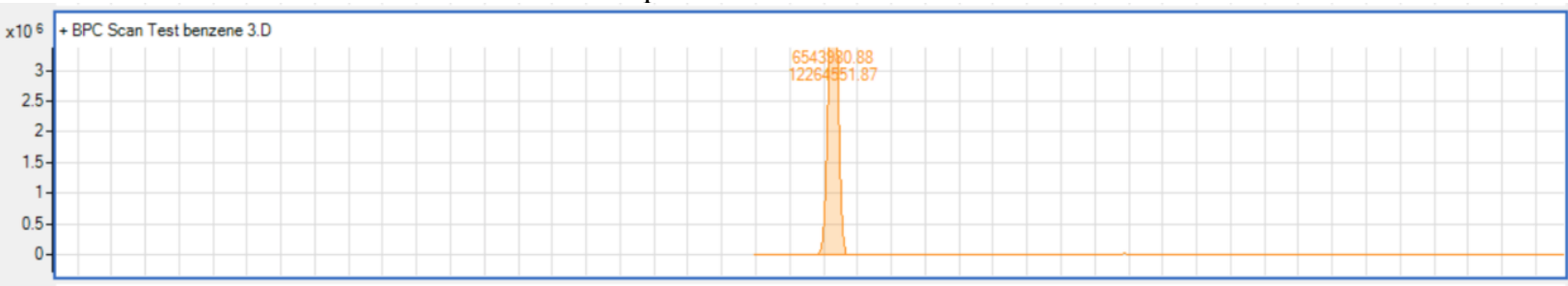

Figure 7. Sample III Spectrogram

Sample IV - HS unburned

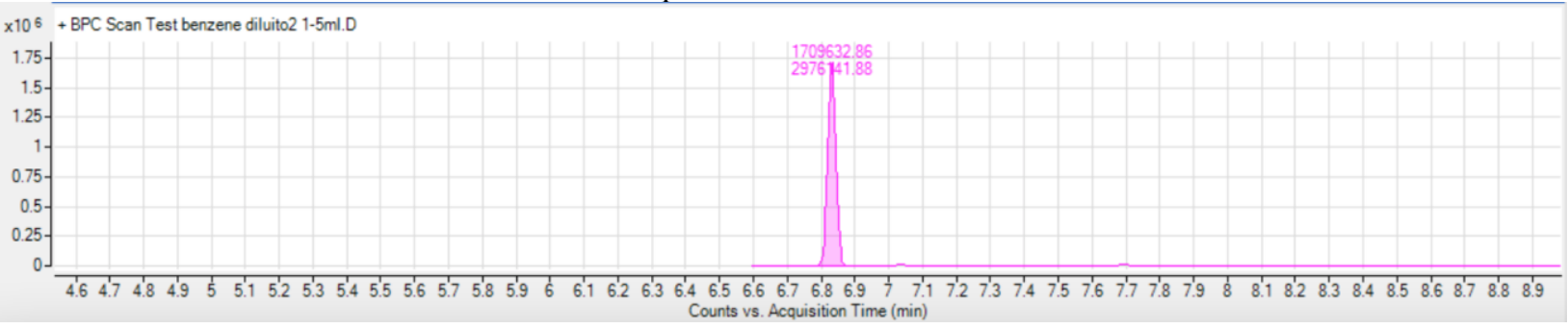

Figure 8. Sample IV Spectrogram

\section{CONCLUSIONS}

As expected, Flame Accelerating Compounds were found most strongly in the unburned III-SPME samples with a peak of $6,5 \times 1012$ and in the unburned IV-HS sample with a peak of $1,7 \times 1012$.

In the burned I-HS sample, benzene is found exclusively with a peak of $3.3 \times 106$, while in the burned II-SPME sample, a benzene peak of 2,9 x 106 is found, with another 3 peaks of flame accelerators which, in all other techniques, are not detected.

The abundance of the substance passing through the section of the column that reaches the mass spectrometer is used as the unit of measurement [29].

This means that:

- With analytical methods of GC-MS it is still possible to find flame accelerants after combustion of textile material;

- The SPME fiber is very performing for the goal to be achieved, because it is able to detail the flame accelerating compounds found [30].

These results, which will be the subject of subsequent studies, bring important perspectives in the field of flame accelerators research on combustible materials. The idea is to develop, starting from this base and with subsequent experiments, a method that enhances the presence of accelerators in order to make their presence even more evident.

In the case of development perspectives that are compatible with forensic work, great attention must be paid to the way in which the samples will be taken from the environment in order to minimize the evaporation of the accelerator.

\section{REFERENCES}

[1] Sparkman, O.D., Penton, Z., Kitson, F.G. (2011). Gas chromatography and mass spectrometry: A practical guide. Academic Press.

[2] Thermo Instrument Systems Inc. History. International Directory of Company Histories (Volume 11 ed.). St. James Press. 1995. pp. 513-514. Retrieved 23 January 2015.

[3] Smith, P.A., Koch, D., Hook, G.L., Erickson, R.P., Lepage, C.R.J., Wyatt, H.D., Eckenrode, B.A. (2004). Detection of gas-phase chemical warfare agents using field-portable gas chromatography-mass spectrometry systems: instrument and sampling strategy considerations. TrAC Trends in Analytical Chemistry, 23(4): 296-306. https://doi.org/10.1016/S01659936(04)00405-4

[4] Dong, C.D., Chen, C.F., Chen, C.W. (2012). Determination of polycyclic aromatic hydrocarbons in industrial harbor sediments by GC-MS. International Journal of Environmental Research and Public Health, 9(6): 2175-2188. https://doi.org/10.3390/ijerph9062175

[5] Andrews, G.E., Bradley, D. (1972). Determination of burning velocities: A critical review. Combustion and Flame, 18(1): 133-153. https://doi.org/10.1016/S00102180(72)80234-7

[6] Hine, G.A. (2004). Fire Scene Investigation: An Introduction. Analysis and Interpretation of Fire Scene Evidence, 33.

[7] Peluso G., Incendi e repertamento, ISA, Corso di 
"Procedure e Tecniche di Investigazione Antincendi", Roma 31 marzo 2009 URL: http://www.vigilfuoco.it.

[8] Schummer, C., Delhomme, O., Appenzeller, B.M., Wennig, R., Millet, M. (2009). Comparison of MTBSTFA and BSTFA in derivatization reactions of polar compounds prior to GC/MS analysis. Talanta, 77(4) 1473-1482.

https://doi.org/10.1016/j.talanta.2008.09.043

[9] NFPA 921. GUIDE FOR fire and Explosion Investigation, 2004 URL https://www.nfpa.org/.

[10] Bergthorson, J.M., Dimotakis, P.E. (2007). Premixed laminar $\mathrm{C} 1-\mathrm{C} 2$ stagnation flames: Experiments and simulations with detailed thermochemistry models. Proceedings of the Combustion Institute, 31(1): 11391147. https://doi.org/10.1016/j.proci.2006.07.110

[11] Wallace, M.A.G., Pleil, J.D., Oliver, K.D., Whitaker, D.A., Mentese, S., Fent, K.W., Horn, G.P. (2019). Targeted GC-MS analysis of firefighters' exhaled breath: Exploring biomarker response at the individual level. Journal of Occupational and Environmental Hygiene, 16(5): 355-366. https://doi.org/10.1080/15459624.2019.1588973

[12] Egolfopoulos, F.N., Hansen, N., Ju, Y., KohseHöinghaus, K., Law, C.K., Qi, F. (2014). Advances and challenges in laminar flame experiments and implications for combustion chemistry. Progress in Energy and Combustion Science, 43: 36-67. https://doi.org/10.1016/j.pecs.2014.04.004

[13] Fang, M., Ivanisevic, J., Benton, H.P., Johnson, C.H., Patti, G.J., Hoang, L.T., Siuzdak, G. (2015). Thermal degradation of small molecules: A global metabolomic investigation. Analytical Chemistry, 87(21): $10935-$ 10941. https://doi.org/10.1021/acs.analchem.5b03003

[14] McMaster, M. (2008). GC/MS A Practical Users Guide. (Wiley-VCH: New York, 1998) ISBN: 978-0-47010163-6

[15] Amirav, A. (2001). The future of GC detectors in the era of mass spectrometry detection. American Laboratory (Fairfield), 33(20): 28-34.

[16] Aldrich, S.S. (1998). Solid phase microextraction: theory and optimization of conditions. Boletin, 923: 154.

[17] Smith, P.A., Sng, M.T., Eckenrode, B.A., Leow, S.Y., Koch, D., Erickson, R.P., Hook, G.L. (2005). Towards smaller and faster gas chromatography-mass spectrometry systems for field chemical detection. Journal of Chromatography A, 1067(1-2): 285-294. https://doi.org/10.1016/j.chroma.2004.11.008

[18] National Institute of Standards and Technology (NIST);
NIST/EPA/NIH MS/MS Mass Spectral Library 2017

URL: https://chemdata.nist.gov;

[19] Gohlke, R.S., McLafferty, F.W. (1993). Early gas chromatography/mass spectrometry. Journal of the American Society for Mass Spectrometry, 4(5): 367-371. https://doi.org/10.1016/1044-0305(93)85001-E

[20] ASTM International. (2004). Standard Test Method for Sensory Analysis: Triangle Test. ASTM International.

[21] Lentini, J.J. (2018). Scientific Protocols for Fire Investigation. CRC Press. https://doi.org/10.4324/9781315178097

[22] Müller, U.C., Bollig, M., Peters, N. (1997). Approximations for burning velocities and Markstein numbers for lean hydrocarbon and methanol flames. Combustion and Flame, 108(3): 349-356. https://doi.org/10.1016/S0010-2180(96)00110-1

[23] Chen, Y.C., Bilger, R.W. (2002). Experimental investigation of three-dimensional flame-front structure in premixed turbulent combustion-I: hydrocarbon/air bunsen flames. Combustion and Flame, 131(4): 400-435. https://doi.org/10.1016/S0010-2180(02)00418-2

[24] Eckenrode, B.A. (2001). Environmental and forensic applications of field-portable GC-MS: an overview. Journal of the American Society for Mass Spectrometry, 12(6): 683-693. https://doi.org/10.1016/S10440305(01)00251-3

[25] Bouvet, N., Chauveau, C., Gökalp, I., Halter, F. (2011). Experimental studies of the fundamental flame speeds of syngas $(\mathrm{H} 2 / \mathrm{CO}) /$ air mixtures. Proceedings of the Combustion Institute, 33(1): 913-920. https://doi.org/10.1016/j.proci.2010.05.088

[26] Cardello, H.M.A.B., Silva, M.A.A.P., Damasio, M.H., Lobao, F. (2003). Programa sistema de coleta de dados tempo-intensidade. Boletim sbCTA, 37: 54-60.

[27] Gohlke, R.S. (1959). Time-of-flight mass spectrometry and gas-liquid partition chromatography. Analytical Chemistry, 31(4): 535-541.

[28] Hites, R.A. (2016). Development of gas chromatographic mass spectrometry. Analytical Chemistry, 88(14): 69556961. https://doi.org/10.1021/acs.analchem.6b01628

[29] Jones M. Gas Chromatography-Mass Spectrometry, American Chemical Society. http://eprints.hud.ac.uk/id/eprint/18978/, accessed on 19 Nov 2019.

[30] Bechtold, J.K., Matalon, M. (2001). The dependence of the Markstein length on stoichiometry. Combustion and Flame, 127(1-2): 1906-1913. https://doi.org/10.1016/S0010-2180(01)00297-8 